\section{Secure care can help youth reduce imminent risk of serious harm and prevent unnecessary death}

British Columbia (BC) is the epicentre of the illicit drug overdose crisis in Canada. There were 1422 deaths from overdose in 2017; 23 of these deaths occurred in children (aged 10-18 yr). ${ }^{1}$ Rates of death from illicit drug use in this age group doubled between 2015 and 2016, and doubled again between 2016 and 2017.

The BC Coroners Service has reported that $31 \%$ of youth with fatal overdoses had a previous nonfatal overdose, ${ }^{2}$ an association also described in adults. ${ }^{3}$ It is therefore understandable that the families and caregivers of youth with dangerous substance use disorders have called upon the province of $\mathrm{BC}$ to join the rest of Canada and provide mandated care, or secure care, for youth with dangerous patterns of drug use who refuse voluntary treatment. ${ }^{4,5}$ Some, however, oppose mandated care.

In a recent CMAJ commentary, Pilarinos and colleagues state, "existing evidence suggests that mandatory addiction treatment does not lead to significant improvements in substance use outcomes." ${ }^{6}$ The meta-analysis by TannerSmith, cited to support this assertion, comes to no such conclusion. The authors compared traditional youth courts with juvenile drug courts and concluded that "[juvenile] drug courts were not found to be categorically more or less effective than traditional court processing for reducing recidivism or drug use. The great variability in effects, nonetheless, suggests that there may be effective drug courts."

Pilarinos and colleagues also state, "A systematic review of studies on courtmandated treatment ... found that forced treatment did not improve outcomes for substance use." ${ }^{6}$ In fact, the publication cited as evidence examined claims that mandated care was superior to voluntary care and concluded, "Regrettably, 3 decades of research into the effectiveness of compulsory treatment have yielded a mixed, inconsistent and inconclusive pattern of results, calling in to question ... claims ... that ... compulsory treatment is effective."

We agree there continues to be no conclusive evidence that secure care is superior to voluntary treatment, but no group is proposing secure care for those who engage in voluntary treatment. More importantly, there are no studies that compare mandated care with supportive care combined with the hope that a youth will enter into voluntary treatment. This is the status quo in $B C$, but the evidence suggests that waiting in hope for youth with serious substance use disorders to realize they need help to stop a dangerous cycle of opioid use is dangerously optimistic.

A lack of evidence of effectiveness of an intervention is not evidence of a lack of effectiveness. We therefore suggest that clinicians and policy-makers review the experience from elsewhere in Canada. Calgary-based Hull Services has provided mandated care to at-risk youth for more than 3 decades. Its priority is to rescue the youth from imminent risk of serious harm or death. Its secondary goals are to assess the overall needs of the youth; stabilize (manage withdrawals, provide opioid agonist therapy, if indicated; feed, clothe and provide safe and secure housing); develop and begin a treatment plan; reconnect the youth with family and community resources; and then discharge the youth into a voluntary system of care. Hull Services reports that $78 \%$ of youth meet these goals with 2 or fewer cycles. Notably, $90 \%$ of youth who were involuntarily placed in the secure care program stated that the program was of benefit to them, and $77 \%$ would recommend it to their friends.

The decision to mandate treatment against a patient's wishes is predicated on the assumption that the individual is not competent to make their own medical decisions and, as a result, is at risk for serious harm. Mandated care is used for some adolescents with severe eating disorders, based on the premise that the disorder and accompanying starvation has seriously impaired judgment and capacity, therefore placing the youth at risk of death. We feel the same principles should be applied to youth with lifethreatening substance use disorders.

We respect patient autonomy; however, in the case of minors, we must balance that with a duty to protect, particularly when life is in danger. Autonomy must be balanced with the developmental level of the patient, impairment related to drug exposure, and severity of risk. Capacity in adolescents is not assumed; it is in development, dynamic and context specific. It is not developmentally appropriate to treat adolescents with severe substance use or other mental health disorders in the same way as adults. In extreme and life-threatening cases, keeping young people alive should be our primary goal.

Secure care is not a panacea and must be nested in a fabric of comprehensive care. When caring for Indigenous youth, we must be cognizant of the legacy of the residential school system and the Sixties Scoop. We encourage BC to heed the 2016 recommendation by Dr. Mary Ellen Turpel-Lafond, an internationally recognized expert on children's human rights, and the then BC Representative for Children and Youth, who stated that the province of $B C$ should construct a comprehensive system for young people that includes community-based and residential treatment services up to and including secure care. ${ }^{9}$

\section{Tom Warshawski MD}

Pediatrician, BC Pediatric Society Secure Care Working Group, Kelowna, BC

\section{Grant Charles PhD RSW}

Social worker, School of Social Work, University of British Columbia, Vancouver, $\mathrm{BC}$

\section{Dzung Vo MD}

Head, Division of Adolescent Health and Medicine, BC Children's Hospital, Vancouver, BC

\section{Eva Moore MD MSPH}

Division of Adolescent Health and Medicine, BC Children's Hospital, Vancouver, BC 


\section{Sara Jassemi MD}

Division of Adolescent Health and Medicine, BC Children's Hospital, Vancouver, BC

Cite as: CMAJ 2019 February 19;191: E197-8. doi: 10.1503/cmaj.71451

\section{References}

1. Fentanyl-detected illicit drug overdose deaths, January 1, 2012 to December 31, 2017. Burnaby (BC): Ministry of Public Safety and Solicitor General, BC Coroners Service; 2018. Available: www.vsb.bc.ca/Repository/SBAttachments/a45 ab349-8cb4-49ae-a2f8-72bed2a717be fentanyl -detected-overdosedeathsJan1.2012toDec31. 2017.pdf (accessed 2018 Oct. 10).
2. Preventing death after overdose: a review of overdose deaths in youth and young adults 2009-2013. Burnaby (BC): Ministry of Public Safety and Solicitor General, BC Coroners Service; 2014. Available: www2.gov.bc.ca/assets/ gov/public-safety-and-emergency-services/death -investigation/child-death-review-unit/reports -publications/overdose-death-youth-young-adult .pdf (accessed 2018 May 10).

3. Caudarella A, Dong J, Milloy MJ, et al. Non-fatal overdose as a risk factor for subsequent fatal overdose among people who inject drugs. Drug Alcohol Depend 2016;162:51-5.

4. BC urgently needs secure care laws for at risk youth, children's representative says. CBC News; updated 2016 May 5. Available: www.cbc.ca/news/canada/ british-columbia/bc-children-representative-at-risk -youth-1.3569265 (accessed 2018 Nov. 10).

5. Smart A. Victoria father wants the right to force teenage daughter into rehab. CBC News; updated
2017 May 8. Available: https://vancouversun.com/ news/local-news/victoria-father-wants-the-right-to -force-teenage-daughter-into-rehab (accessed 2018 Nov. 10).

6. Pilarinos A, Kendall P, Fast D, et al. Secure care: more harm than good. CMAJ 2018;190:E1219-20.

7. Tanner-Smith EE, Lipsey MW, Wilson DB. Juvenile drug court effects on recidivism and drug use: a systematic review and meta-analysis. J Exp Criminol 2016;12:511-2.

8. Klag S, O'Callaghan F, Creed P. The use of legal coercion in the treatment of substance abusers: an overview and critical analysis of thirty years of research. Subst Use Misuse 2005;40: 1777-95.

9. Last resort: one family's tragic struggle to find help for their son. Victoria (BC): Representative for Children and Youth; 2016.

Competing interests: None declared. 